\title{
Assessment of microsatellite instability status for the prediction of metachronous recurrence after initial endoscopic submucosal dissection for early gastric cancer
}

\author{
T Hasuo', S Semba', D Li', Y Omori', D Shirasaka ${ }^{2,3}$, N Aoyama $^{2}$ and H Yokozaki*, \\ 'Division of Surgical Pathology, Department of Biomedical Informatics, Kobe University Graduate School of Medicine, Kobe, Japan; ${ }^{2}$ Department of \\ Endoscopy and Division of Diabetes, Digestive and Kidney Diseases, Kobe University Graduate School of Medicine, Kobe, Japan; ${ }^{3}$ Division of Cellular and \\ Molecular Medicine, Kobe University Graduate School of Medicine, Kobe, Japan
}

\begin{abstract}
The technique of endoscopic submucosal dissection (ESD) has been developed for en bloc resection of early gastric cancer (EGC); however, little is known about the risk of metachronous cancer in the remnant stomach after initial ESD. In this study, we investigated the correlation between microsatellite instability (MSI) status and the incidence of metachronous recurrence of gastric cancer. According to the genetic/molecular background determined with MSI status and expression levels of hMLHI and p53 tumour suppressor, I 10 EGCs removed with ESD were subclassified into three groups: the mutator/MSI-type (8\%), suppressor/p53-type (45\%) and unclassified type (47\%). Interestingly, patients with the mutator/MSI-type tumour had a high incidence (67\%) of metachronous recurrence of gastric cancer within a 3-year observation after initial ESD, which was significantly higher than those with the suppressor/p53-type and unclassified type tumours $(P<0.0 \mathrm{I})$. Although we investigated mucin phenotypes, there was no correlation between mucin phenotype and the recurrence of EGC. These findings suggest that subclassification of molecular pathological pathways in EGCs is required for the assessment of patients with a high risk of recurrent gastric cancer. The information delivered from our investigation is expected to be of value for decisions about therapy and surveillance after ESD.

British Journal of Cancer (2007) 96, 89-94. doi:10.1038/sj.bjc.6603532 www.bjcancer.com

Published online 19 December 2006

(c) 2007 Cancer Research UK
\end{abstract}

Keywords: microsatellite instability (MSI); early gastric cancer (EGC); endoscopic submucosal dissection (ESD); metachronous recurrent cancer

Gastric cancer is the second-most-frequent malignant tumour worldwide, but the consequences of early gastric cancer (EGC) are comparatively good (Correa, 1992). In particular, endoscopic treatment is being widely used to treat patients with EGC and carries with it some improvement for their prognosis; therefore, many patients suffering from EGC have avoided laparotomy and maintained a better quality of life (Nagano et al, 2005). Endoscopic resection of EGC is now the standard therapy in Japan and is increasingly becoming accepted and regularly used in other countries. Recently, an innovational technique for endoscopic submucosal dissection (ESD) has been developed for en bloc resection of ECG (Ono et al, 2001). In addition, the ESD method has made it possible to give an accurate diagnosis by pathological examination (Toyonaga et al, 2006). However, metachronous recurrence at other sites in the stomach, after initial endoscopic treatment, has been identified as a major problem (Hamanaka and Gotoda, 2005).

Based on the tendency of gland formation, gastric carcinomas have been divided into two main histological types: diffuse-type carcinomas, which may arise from native gastric epithelial cells,

*Correspondence: Dr H Yokozaki; E-mail: hyoko@med.kobe-u.ac.jp Received 21 August 2006; revised 30 October 2006; accepted 14 November 2006; published online 19 December 2006 and intestinal-type carcinomas, which were thought to arise from gastric epithelial cells that have undergone intestinal metaplasia (Lauren, 1965; Nakamura et al, 1968; Tahara, 1995). Current accepted indications for ESD of EGC include the resection of small intramucosal EGC of the intestinal type; the development of ESD techniques enables resection of larger lesions than has been technically feasible by simple endoscopic mucosal resection (EMR). However, the rationale behind this recommendation was that larger size lesions, or lesions with diffuse histology type, may extend into the submucosal layer and thus have a higher risk of lymph node metastasis. Therefore, at present, the accepted indications for ESD are: (i) well-differentiated elevated cancers less than $2 \mathrm{~cm}$ in size and (ii) small $(\leqslant 1 \mathrm{~cm})$ depressed lesions without ulceration (Japanese Gastric Cancer Association, 2001). These lesions must also be moderately or well differentiated and confined to the mucosa, and must not have lymphatic or vascular involvement; well-differentiated type adenocarcinomas correspond to the intestinal-type (Lauren, 1965), the expanding-type (Ming, 1977) and the differentiated carcinoma (Nakamura et al, 1968).

Recent molecular biological studies have revealed that there are at least two distinct genetic pathways for gastrointestinal carcinogenesis, the suppressor and mutator pathways (Parsons et al, 1993; Eshleman and Markowitz, 1996). The suppressor/p53 pathway is mainly caused by inactivation of tumour suppressor genes and the activation of oncogenes. $p 53$ is a tumour suppressor 
that is frequently mutated in human cancer and is believed to play an important role in defending against cancer (Tamura et al, 1995). Microsatellite instability (MSI) is closely correlated with genetic instability, particularly in hereditary nonpolyposis colorectal cancer (HNPCC) (Fishel et al, 1993; Peltomalo et al, 1993). Dysfunction of the DNA mismatch repair system leads to the mutator pathway showing MSI; thus, MSI can be identified in tumours when alleles of novel sizes are detected in microsatellite sequences derived from cancer DNA that are not present in the normal tissue of the same individual. It has been documented that $15-33 \%$ of human gastric cancers exhibit MSI and that MSI is frequently observed in well-differentiated adenocarcinoma (Mironov et al, 1994; Semba et al, 1996). Furthermore, MSI was observed more frequently in patients with synchronous multiple gastric tumours than in those with a single tumour (Nakashima et al, 1995).

In this study, we focused on the metachronous recurrence of gastric cancer after removal of EGC (well-differentiated type) with ESD. After initial dissection, we subclassified these patients into three groups according to molecular findings and followed them endoscopically for several years to monitor the recurrence of gastric cancer.

\section{MATERIALS AND METHODS}

\section{Patients and DNA extraction}

The series consisted of 110 patients who had undergone curative resections for EGC with ESD at the Kobe University Hospital from 2000 to 2004. Their clinical and histological characteristics are summarised in Table 1. Informed consent for the scientific analysis of resected specimens was obtained from all patients, including those who had no hereditary cancer syndrome history, such as HNPCC, Li-Fraumeni syndrome and familial adenomatous polyposis (FAP), and those who had hereditary diffuse gastric cancer (HDGC). All resected specimens were fixed in $10 \%$ formalin and embedded in paraffin. Histopathological examination was performed according to the Japanese Classification of Gastric Carcinoma 2nd edition (Japanese Gastric Cancer Association, 2001). Early gastric cancers were defined as cancers in which invasion was limited to the submucosal layer, irrespective of the presence or absence of metastasis to lymph nodes. To exclude the incidence of local recurrence after initial ESD treatment, the histological curative resection was determined as follows; depth $\mathrm{M}$ (mucosa), histologically well differentiated adenocarcinoma (tub1 or tub2), neither lymphatic nor venous invasion, no tumour cells within $1 \mathrm{~mm}$ of lateral margin ( $1 \mathrm{~mm}$ lateral margin approximately

Table I Clinical and histological characteristics of early gastric cancers

\begin{tabular}{|c|c|c|c|}
\hline Characteristic & Group & No. & (\%) \\
\hline \multirow[t]{2}{*}{ Gender } & Male & 74 & (67) \\
\hline & Female & 36 & (33) \\
\hline \multirow[t]{2}{*}{$\operatorname{Age}^{a}$ (year) } & $<65$ & 53 & (48) \\
\hline & $\geqslant 65$ & 57 & (52) \\
\hline \multirow[t]{2}{*}{ Tumour size $(\mathrm{cm})$} & $<2$ & 67 & $(61)$ \\
\hline & $\geqslant 2$ & 43 & (39) \\
\hline \multirow[t]{3}{*}{ Location $^{b}$} & Upper & 30 & (27) \\
\hline & Middle & 31 & (28) \\
\hline & Lower & 49 & (45) \\
\hline \multirow[t]{2}{*}{ Differentiation $^{b}$} & tubl & 84 & (76) \\
\hline & tub2 & 26 & (24) \\
\hline
\end{tabular}

${ }^{\mathrm{a}}$ Average age (years); $65.3+7.3$. $^{\mathrm{b}}$ Location of tumours and histological differentiation were determined according to the Japanese Classification of Gastric Cancer 2nd edition. $\quad$ tubl $=$ well-differentiated tubular adenocarcinoma, tub2 = moderately differentiated tubular adenocarcinoma. corresponds to the length of ten tubules). The cases positive for lateral or vertical margins were therefore avoided in this study.

Selected blocks were sectioned into $4 \mu \mathrm{m}$-thick slices for DNA extraction and immunohistochemical analysis. For DNA extraction, the deparaffinised specimens were stained with haematoxylin and eosin $(\mathrm{H} \& \mathrm{E})$. The tumour areas and corresponding nonneoplastic gastric mucosa were scraped using a sterile needle and placed in a microtube containing extraction buffer before being incubated at $55^{\circ} \mathrm{C}$ for $12 \mathrm{~h}$ as described elsewhere (Wu et al, 2004). Proteinase $\mathrm{K}$ was inactivated by boiling for $5 \mathrm{~min}$ after inactivation and then the DNAs were used for polymerase chain reaction (PCR).

\section{Immunohistochemistry}

Immunohistochemical analyses were carried out with monoclonal antibodies to p53 (DakoCytomation, Copenhagen, Denmark), hMLH1 (BD Biosciences, San Diego, CA, USA), CD10 (Novocastra Laboratories, Newcastle-upon-Tyne, UK), MUC2 (Santa Cruz Biotechnology, Santa Cruz, CA, USA), MUC5AC (Novocastra Laboratories) and MUC6 (Novocastra Laboratories). Dewaxed and rehydrated specimens were autoclaved in citrate buffer for the antigen retrieval. Endogenous peroxidase activity and nonspecific binding were blocked by $0.03 \%$ hydrogen peroxidase in methanol and blocking reagent in LSAB2 kit (DakoCytomation), respectively. The slides were then incubated with the primary monoclonal antibody and incubated sequentially with a biotinylated secondary antibody, streptavidin, labelled with peroxidase and 3, 3 -diaminobenzidine. Slides were counterstained with Mayer's haematoxylin. Immunoreactivity of p53 and hMLH1 was graded as follows: almost no positive cells;,$+<25 \%$ of the tumour cells showed positive immunoreactivity;,$++ 25-50 \%$ of the tumour cells showed positive immunoreactivity;,$+++>50 \%$ of the tumour cells showed positive immunoreactivity (Li et al, 2005).

\section{Microsatellite analysis}

Nine microsatellite markers (BAT-25, BAT-26, BAT-40, BAT-RII, D1S191, D2S123, D5S346, D17S250 and D17S855) were analysed (Li et al, 2005). The forward primers were fluorescein labelled with 6-FAM (D1S191, D17S250, BAT-26 and BAT-40), HEX (D17S855 and BAT-RII), VIC (D5S346) and TAMRA (D2S123 and BAT-25). PCR was performed in $15 \mu \mathrm{l}$ reaction volumes containing $1 \mu \mathrm{l}$ template DNA, $0.56 \mu \mathrm{moll}^{-1}$ of each primer, $74.7 \mu \mathrm{moll}^{-1}$ of dNTP, $4.5 \mu \mathrm{moll}^{-1}$ of $\mathrm{MgCl}_{2}$ and $0.075 \mathrm{U}$ of AmpliTaq Gold (Applied Biosystems, Foster City, CA, USA). After the initial Taq DNA polymerase activation step, the PCR amplification consisted of 45 cycles $\left(94^{\circ} \mathrm{C}\right.$ for $45 \mathrm{~s}, 55^{\circ} \mathrm{C}$ for $45 \mathrm{~s}$ and $72^{\circ} \mathrm{C}$ for $\left.45 \mathrm{~s}\right)$ followed by a final extension for $10 \mathrm{~min}$ at $72^{\circ} \mathrm{C}$. Polymerase chain reaction products were electrophoresed in ABI PRISM 310 Genetic Analyzer along with GeneScan-500 (ROX) molecular weight standard (Applied Biosystems). The size of the PCR product was analysed using GeneScan software (Applied Biosystems). The status of MSI in each tumour was evaluated according to the criterion of Boland et al (1998); MSI-H, if three or more out of nine microsatellite loci showed MSI; MSI-L, if one or two loci had MSI; MSS, if all the microsatellite loci examined were stable. Alleles were defined as the two highest peaks (tumour DNA alleles, T1, T2; normal DNA alleles, N1, N2) and a ratio of $(\mathrm{T} 1 / \mathrm{T} 2) /(\mathrm{N} 1 / \mathrm{N} 2)$ of $<0.67$ or $>1.50$ was scored as a loss of heterozygosity (LOH) (Wu et al, 2004).

\section{Subclassification of mucin phenotypes}

The extent of positivity for MUC2, MUC5AC, MUC6 and CD10 was scored according to the percentage of neoplastic cells stained: - , no positive cells or essentially none $(<5 \%) ;+$, some positive cells $(5-30 \%) ;++$, well-defined areas of positive cells $(30-60 \%)$; 
+++ , extensive areas of positive cells $(>60 \%)$. According to the sums of scores of gastric markers (MUC5AC, MUC6) and intestinal markers (MUC2, CD10), each case was phenotypically classified into three phenotypes: the gastric phenotype, mixed phenotype and intestinal phenotype (Tsukashita et al, 2001).

\section{Statistical analysis}

Statistical comparisons were performed using the Fisher's protected least significant difference test, the $\chi^{2}$ test, the log-rank test and the Kaplan-Meier test for three independent groups. $P$-values of 0.05 or less were considered to indicate statistical significance. All statistical analyses were performed using Statview 5.0 software (SAS Institute Inc., Cary, NC, USA).
A Mutator/MSI-type
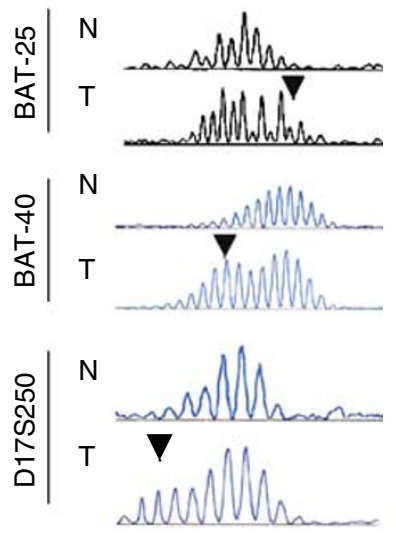

C
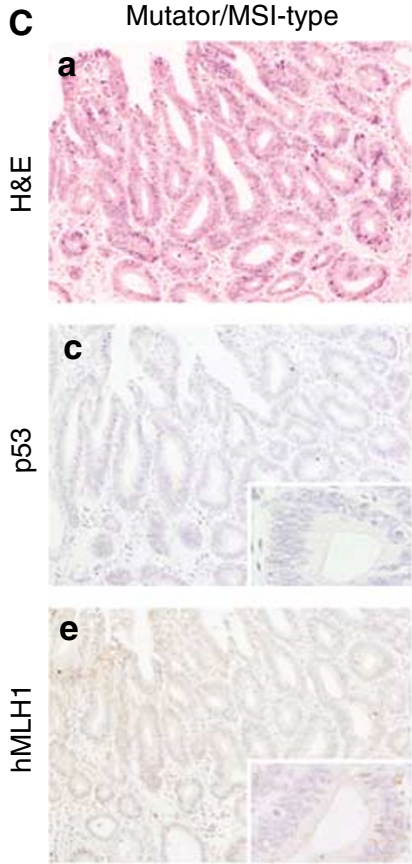

B Suppressor/p53-type

D17S250 LOH

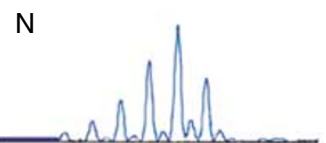

$\mathrm{T}$

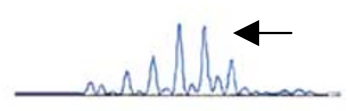

Suppressor/p53-type
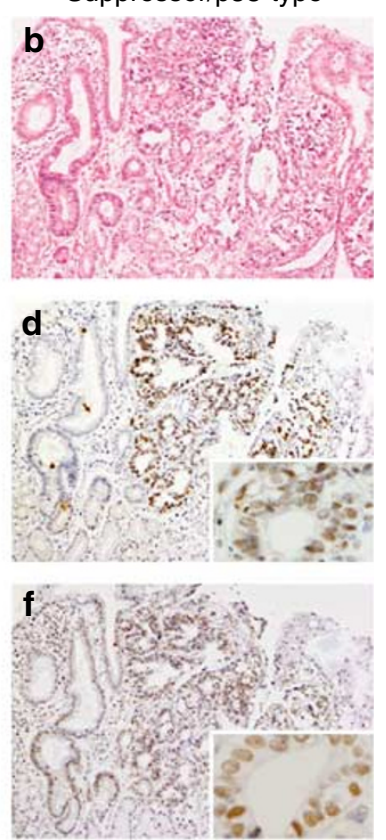

Figure I Representative results of microsatellite assay and immunohistochemistry. (A) Results of microsatellite analysis on BAT-25, BAT-40 and DI7S250. Arrowheads indicate MSI. N, normal mucosa; T, tumour. (B) Loss of heterozygosity at the p53 locus (DI7S250). Decreased peak levels in tumour are regarded as $\mathrm{LOH}$ (arrow). N, normal mucosa; T, tumour. (C) Histological examination of EGCs. Representative mutator/MSI-type (a, c, e; $\times 100)$ and suppressor/p53-type $(b, \mathrm{~d}, \mathrm{f} ; \times 100)$ tumours are illustrated. a-b, H\&E.; c-d, p53; d-f, hMLHI (inset original magnification $\times 400$ ).

\section{RESULTS}

Subclassification of EGC with genetic background: the mutator/MSI-type and suppressor/p53-type

To determine the genetic background of each tumour, we first performed a microsatellite assay in tumours with microsatellite markers (Figure 1A). Overall, MSI was detected in 25 (23\%) of 110 cases (MSI-H, nine (8\%) cases; MSI-L, $16(15 \%)$ cases) and LOH at the $p 53$ locus (D17S250) was detected in eight (7\%) of 110 cases (Figure 1B and 2). Next, we investigated the levels of p53 and hMLH1 expression immunohistochemically to distinguish the mutator/MSI-type tumours and suppressor/p53-type tumours. Strong nuclear accumulation of p53 $(++,+++)$ was detected in $47(43 \%)$ cases and loss of hMLH1 expression (-) was detected in $28(25 \%)$ cases, respectively (Figures $1 \mathrm{C}$ and 2 ).

Two distinct pathways, the mutator and suppressor pathways, have been proposed for colorectal carcinogenesis (Parsons et al, 1993). Similarly, this concept is believed to be available for subclassification of human gastric cancers (Yamamoto et al, 1995;

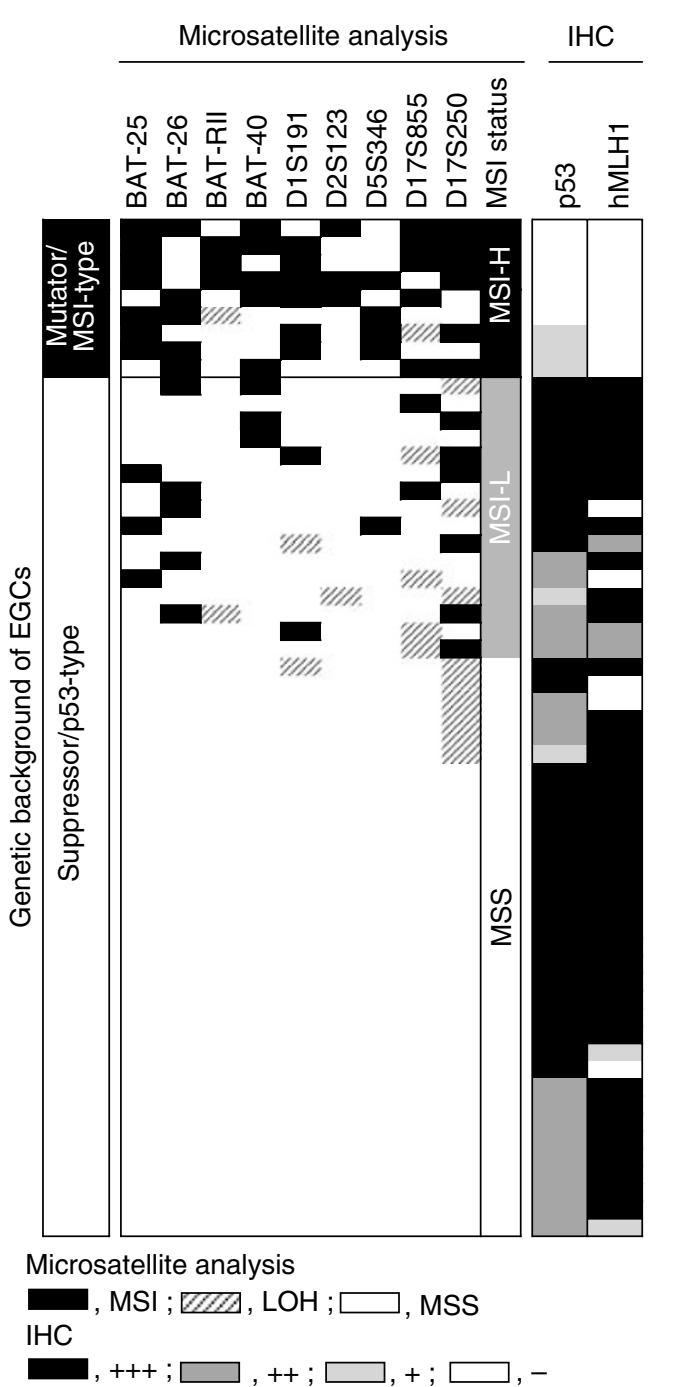

Figure 2 Results of microsatellite assay and immunohistochemical analyses (IHC) in the mutator/MSI-type and suppressor/p53-type human EGCs. The status of microsatellite sequences was determined as described in the text. Immunoreactivity of p53 and hMLHI was graded from - to +++ . According to these results, tumours were subclassified into the mutator/MSI-type, suppressor/p53-type, and unclassified type tumours. 
Semba et al, 1996; Endoh et al, 2000; Furlan et al, 2002; Wu et al, 2004). Therefore, we attempted to subclassify these EGCs with the definition of the mutator (mutator/MSI-type) and suppressor (suppressor/p53-type) pathways (Eshleman and Markowitz, 1996). According to the results of genetic and immunohistochemical analyses, we therefore subclassified these EGCs into three subtypes: the mutator/MSI-type (tumours with MSI-H and loss of hMLH1 expression), nine (8\%) cases; suppressor/p53-type (tumour with strong p53 expression, or with LOH at D17S250), $49(45 \%)$ cases and unclassified type, $52(47 \%)$ cases (Figure 2 and Table 2). All of the cases of the mutator/MSI-type tumours showed loss of hMLH1 expression, whereas 41 of 49 (84\%) and 27 of 52 $(52 \%)$ cases in the suppressor/p53 and unclassified types had strong expression of hMLH1. No significant correlation was found between genetic type and clinicopathological parameters.

\section{Expression of epithelial mucin in EGCs}

We investigated mucin expression in these EGCs because a previous study reported that subclassification of gastric cancer mucin is likely to be useful in predicting the pattern of gastric carcinoma recurrence after curative surgery (Tajima et al, 2004). According to the results of immunohistochemical analyses of epithelial mucin expression, the EGCs were classified into three mucin phenotypes: the gastric phenotype, 50 (46\%) cases; mixed phenotype, $17(15 \%)$ cases and intestinal phenotype, 43 (39\%) cases. There was significant difference between mucin phenotypes and location $(P=0.007)$, but no correlation was found in the other clinicopathological parameters (Table 2).

\section{MSI status is a good marker for the possible development of metachronous cancer}

The patients examined were regularly followed and observed endoscopically to monitor for secondary metachronous tumours in the remnant stomach after ESD. Interestingly, patients with mutator/MSI-type EGCs had a tendency to develop secondary metachronous cancer in the remnant stomach after initial ESD, which was statistically higher than the suppressor/p53 and unclassified type tumours $(P<0.01$, Figure $3 \mathrm{~A})$, whereas no correlation was found in the increase of metachronous gastric cancers by subclassification of tumours with mucin phenotypes $(P=0.84$, Figure 3B). We also investigated MSI and p53 and hMLH1 expression in the metachronous secondary gastric cancers; all secondary tumours arising from patients with the mutator/MSItype EGC also showed MSI and loss of hMLH1 expression (data not shown).

\section{DISCUSSION}

Endoscopic treatment for patients with early-stage gastric carcinoma has been widely used for curative therapy, and such endoscopic tumour resection has enabled patients with gastric cancer to have better prognoses (Haruma et al, 1990; Sano et al, 1992; Amano et al, 1998). Although ESD is a useful method newly developed not only for endoscopic curative resection of EGCs but also for accurate histological diagnosis, the indications for such endoscopic treatment are limited to small, well-differentiated adenocarcinomas with minimal submucosal invasion (Hirasaki et al, 2005; Kato, 2005). Endoscopic treatment excised only gastric carcinoma tissues, which implies that patients are still at risk of developing metachronous recurrence of gastric cancer. Therefore, molecular diagnosis is required for the screening of patients expected to have metachronous gastric carcinoma (Miyoshi et al, 2001).

This is the first report indicating the clinical usefulness of microsatellite analysis for predicting the potential risk of developing metachronous gastric cancer after curative resection with ESD. Miyoshi et al (2001) examined MSI retrospectively in patients with multiple EGCs and found that MSI increased the frequency of synchronous and metachronous gastric cancer development. However, gastric carcinoma tissues removed with EMR may possibly be related to local recurrence of carcinoma, and

Table 2 Relationship between genetic type/mucin phenotype and clinicopathological parameters in early gastric cancers

\begin{tabular}{|c|c|c|c|c|c|c|c|c|}
\hline & \multicolumn{3}{|c|}{ Genetic type } & $P$-value & \multicolumn{3}{|c|}{ Mucin phenotype } & $P$-value \\
\hline Male & 6 & 32 & 36 & & 34 & 11 & 29 & \\
\hline Female & 3 & 17 & 16 & 0.931 & 16 & 6 & 14 & 0.989 \\
\hline \multicolumn{9}{|l|}{ Age (years) } \\
\hline \multicolumn{9}{|c|}{ Tumour size $(\mathrm{cm})$} \\
\hline$<2$ & 7 & 30 & 30 & & 30 & 9 & 28 & \\
\hline$\geqslant 2$ & 2 & 19 & 21 & 0.774 & 20 & 8 & 15 & 0.840 \\
\hline \multicolumn{9}{|l|}{ Location $^{\mathrm{a}}$} \\
\hline Upper & 2 & 12 & 14 & & 20 & 4 & 6 & \\
\hline \multicolumn{9}{|c|}{ Differentiation $^{\mathrm{a}}$} \\
\hline tub2 & 2 & 11 & 13 & 0.956 & 16 & 4 & 6 & 0.192 \\
\hline Total (\%) & $9(8)$ & $49(45)$ & $52(47)$ & & $50(46)$ & $17(15)$ & $43(39)$ & \\
\hline
\end{tabular}

a Location and histological differentiation of the tumours were determined according to the Japanese Classification of Gastric Cancer 2 nd edition (200I). tubl = welldifferentiated tubular adenocarcinoma, tub2 = moderately differentiated tubular adenocarcinoma. *There was significant difference between mucin phenotypes and location of EGC ( $P=0.007$, Fisher's test). 

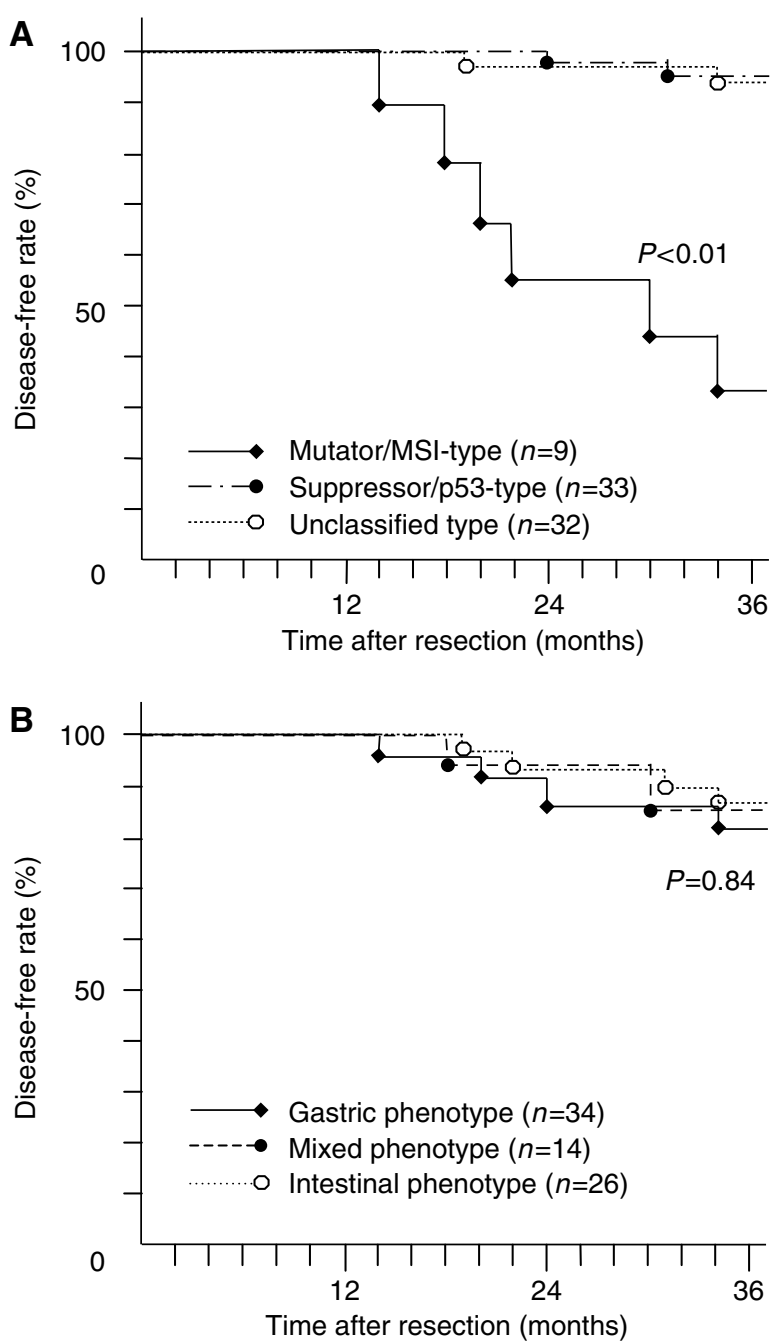

Figure 3 Kaplan-Meier curves for ECG patients who had metachronous cancer after initial ESD treatment. (A) Overall disease-free curves in relation to the mutator/suppressor subtypes in patients with EGCs. The 3-year disease-free rate in the group of mutator/MSI-type tumours was $33 \%$, but it was 93 and $94 \%$ in the suppressor/p53-type and unclassified type tumours, respectively $(P<0.01)$. (B) Overall disease-free curves in relation to mucin subtypes in patients with EGCs. There was no statistical difference in the 3-year disease-free rate among mucin phenotypes $(P=0.84)$

researchers collected multiple EGC tissues with the intention of analysing the relationship between MSI and synchronous and metachronous gastric cancer. In the current study, we could eliminate the local recurrence of gastric cancer because ESD is a more efficient method for curative resection of EGC and enables more accurate histopathological diagnosis than EMR. In addition, our cohort study indicated a high frequency of MSI linked with recurrence of carcinoma in patients with EGC. Thus, subclassification of EGCs into two distinct groups, the mutator/MSI-type and the suppressor/p53-type, may help clinically in defining a molecular marker for the prediction of multiple and metachronous gastric cancer.

Correa (1992) hypothesised that carcinogenesis of the stomach is a multistage process, and the progression from normal epithelial cells to tumour cells involves at least six stages: superficial gastritis, chronic atrophic gastritis, intestinal metaplasia of the complete type followed by the incomplete type, gastric adenoma, dysplasia and carcinoma. Although chronic infection of Helicobacter pylori (H. pylori) (Blaser, 1987) and excess salt and nitrosamine compound intake (Sugimura and Wakabayashi, 1990) are suspected to be important causal factors in gastric carcinogens, little is known about the mechanism through which the incidence of gastric cancer might be increased. In this study, infection of H. pylori was confirmed in all cases, and eradication treatment was performed before or after ESD; the eradication therapeutic success rate was $95 \%$, and a second eradication treatment using another antibiotic was performed in the failure group (data not shown). The data suggest that chronic atrophic gastritis with or without intestinal metaplasia, due to $H$. pylori infection, certainly increases the incidence of gastric cancer, irrespective of the mutator/MSItype or the suppressor/p53-type. However, further genetic changes may finally decide the carcinogenesis pathway for epithelial cells to develop gastric cancer. As reported previously, an MSI-positive genetic background is a risk for developing multiple cancers, including synchronous and metachronous cancer (Miyoshi et al, 2001). As our study indicated that patients with the mutator/ MSI-type EGC are expected to have a higher risk of developing metachronous mutator/MSI-type tumours in the stomach, the assessment of MSI is necessary for following up these patients with MSI-positive EGC.

Tajima et al (2004) showed that the incidence of gastric mucinproducing tumours was significantly higher in tumours with recurrence than in tumours without recurrence after curative surgery, irrespective of their histological type. Their study was performed using advanced cancer; presumably, the results may have been influenced by the other characteristic factors of cancer cells, including resistance to chemotherapy, growth rate and vessel infiltration activity. No significant correlation was found between MSI and mucin phenotype in this series of EGC, in which most tumours demonstrated well-differentiated tubular formation (tub1 and tub2), suggesting that recurrence of gastric cancer may not be controlled by mucin phenotype (Shibata et al, 2003). Although it has also been documented that mucin phenotype may be associated with MSI status (Endoh et al, 2000; Takahashi et al, 2002), our results indicate the opposite conclusion; mucin phenotypes did not connect with genetic alterations in microsatellite loci. Further investigation is required to clarify this discrepancy.

\section{ACKNOWLEDGEMENTS}

We thank A Kawashima, A Obata and K Kimura for their skilful technical assistance, and M Kato for her secretarial assistance. This work was supported in part by Grant-in-Aid for Cancer Research from the Ministry of Health, Labor and Welfare of Japan (14-8), by a Grant-in-Aid for Scientific Research (B) 14370070 from the Ministry of Education, Culture, Sports, Science and Technology of Japan and by the Terry Fox Run Foundation for Cancer Research.

\section{REFERENCES}

Amano Y, Ishihara S, Amano K, Hirakawa K, Adachi K, Fukuda R, Watanabe M, Fukumoto S, Fujishiro H, Imaoka T (1998) An assessment of local curability of endoscopic surgery in early gastric cancer without satisfaction of current therapeutic indications. Endoscopy 30: 548-552
Blaser MJ (1987) Gastric campylobacter-like organisms, gastritis and peptic ulcer disease. Gastroenterology 93: 371 - 383

Boland CR, Thibodeau SN, Hamilton SR, Sidransky D, Eshleman JR, Burt RW, Meltzer SJ, Rodriguez-Bigas MA, Fodde R, Ranzani GN, Srivastava S 
Nakamura K, Sugano H, Takagi K (1968) Carcinoma of the stomach in incipient phase: Its histogenesis and histological appearances. Gann 59: $251-258$

1998) A National Cancer Institute Workshop on Microsatellite Instability for cancer detection and familial predisposition: developmen of international criteria for the determination of microsatellite instability in colorectal cancer. Cancer Res 58: 5248-5257

Correa P (1992) International cancer epidemiology meetings. Cancer Epidemiol Biomarkers Prev 1: 245-247

Endoh Y, Tamura G, Ajioka Y, Watanabe H, Motoyama T (2000) Frequent hypermethylation of $h M L H 1$ gene promoter in differentiated-type tumors of the stomach with the genetic foveolar phenotype. Am J Pathol 157: $717-722$

Eshleman JR, Markowitz SD (1996) Mismatch repair defects in human carcinogenesis. Hum Mol Genet 5: 1489 - 1494

Fishel R, Lescoe MK, Rao MR, Copeland NG, Jenkins NA, Garber J, Kane M, Kolodner R (1993) The human mutator gene homolog MSH2 and its association with hereditary nonpolyposis colon cancer. Cell 75: $1027-1038$

Furlan D, Casati B, Cerutti R, Facco C, Terracciano L, Capella C, Chiaravalli AM (2002) Genetic progression in sporadic endometrial and gastrointestinal cancers with high microsatellite instability. J Pathol 197: $603-609$

Hamanaka H, Gotoda T (2005) Endoscopic resection for early gastric cancer and future expectations. Digestive Endosc 17: 275-285

Haruma K, Sumii K, Inoue K, Teshima H, Kajiyama G (1990) Endoscopic therapy in patients with inoperable early gastric cancer. $A m J$ Gastroenterol 85: $522-526$

Hirasaki S, Tanimizu M, Nasu J, Shinji T, Koide N (2005) Treatment of elderly patients with early gastric cancer by endoscopic submucosal dissection using an insulated-tip diathermic knife. Intern Med 4: $1033-1038$

Japanese Gastric Cancer Association (2001) Japanese classification of gastric carcinoma -2nd English Edition- Response assessment of chemotherapy and radiotherapy for gastric carcinoma: clinical criteria. Gastric Cancer 4: 1-8

Kato H (2005) Endoscopic submucosal dissection (ESD) is being accepted as a new procedure of endoscopic treatment of early gastric cancer. Intern Med 44: $85-86$

Lauren P (1965) The two histological main types of gastric carcinoma: diffuse and so-called intestinal-type carcinoma. Acta Pathol Microbiol Scand A 64: 31 - 49

Li D, Semba S, Wu M, Yokozaki H (2005) Molecular pathological subclassification of mucinous adenocarcinoma of the colorectum. Pathol Int 55: $766-774$

Ming SC (1977) Gastric carcinoma. A pathobiological classification. Cancer 39: $2475-2485$

Mironov NM, Aguelon MA, Poapova GI, Omori Y, Gorbunov OV, Klimenkov AA, Yamasaki $\mathrm{H}$ (1994) Alterations of (CA) $)_{\mathrm{n}}$ repeats and tumor suppressor genes in human gastric cancer. Cancer Res 54: $41-44$

Miyoshi E, Haruma K, Hiyama T, Tanaka S, Yoshihara M, Shimamoto F, Chayama K (2001) Microsatellite instability is a genetic marker for the development of multiple gastric cancers. Int J Cancer 95: 350-353

Nagano H, Ohyama S, Fukunaga T, Seto Y, Fujisaki J, Yamaguchi T, Yamamoto N, Kato Y, Yamaguchi A (2005) Indications for gastrectomy after incomplete EMR for early gastric cancer. Gastric Cancer 8: 149-154
Nakashima H, Honda M, Inoue H, Shibuta K, Arinaga S, Era S, Ueo H, Mori M, Akiyoshi T (1995) Microsatellite instability in multiple gastric cancer. Int J Cancer 64: 239-242

Ono H, Kondo H, Gotoda T, Shirao K, Yamaguchi H, Saito D, Hosokawa K, Shimoda T, Yoshida Y (2001) Endoscopic mucosal resection for treatment of early gastric cancer. Gut 48: 225-229

Parsons R, Li GM, Longley MJ, Fang WH, Papadopoulos N, Jen J, de la Chapelle A, Kinzler KW, Vogelstein B, Modrich P (1993) Hypermutability and mismatch repair deficiency in RER+ tumor cells. Cell 75: $1227-1236$

Peltomalo P, Lothe RA, Aaltonen LA, Pylkkanen L, Nystron-Lahti M, Seruca R, David L, Holm R, Ryberg D, Haugen A (1993) Microsatellite instability is associated with tumors that characterize the hereditary nonpolyposis colorectal carcinoma syndrome. Cancer Res 53: 5853-5855

Sano T, Kobori O, Muto T (1992) Lymph ode metastasis from early gastric cancer: endoscopic resection of tumor. Br J Surg 79: $241-244$

Semba S, Yokozaki H, Yamamoto S, Yasui W, Tahara E (1996) Microsatellite instability in precancerous lesions and adenocarcinomas of the stomach. Cancer 77: 1620-1627

Shibata N, Watari J, Fujita M, Tanno S, Saitoh Y, Kohgo Y (2003) Cell kinetics and genetic instabilities in differentiated type early gastric cancers with different mucin phenotype. Hum Pathol 34: 32-40

Sugimura T, Wakabayashi K (1990) Gastric carcinogenesis: diet as a causative factor. Med Oncol Tumor Pharmacother 7: 87-92

Tahara E (1995) Genetic alterations in human gastrointestinal cancers. The application to molecular diagnosis. Cancer 75: 1410-1417

Tajima K, Nishino N, Morohara K, Yamazaki T, Kaetsu T, Suzuki S, Kawamura M, Kumagai K, Kusano M (2004) Gastric and intestinal phenotype maker expression in gastric carcinomas and recurrence pattern after surgery-immunohistochemical analysis of 213 lesions-. $\mathrm{Br} \mathrm{J}$ Cancer 91: $1342-1348$

Takahashi H, Endo T, Yamashita K, Arimura Y, Yamamoto H, Sasaki S, Itoh F, Hirata K, Imamura A, Kondo M, Sato T, Imai K (2002) Mucin phenotype and microsatellite instability in early multiple gastric cancers. Int J Cancer 100: 419-424

Tamura G, Sakata K, Maesawa C, Suzuki Y, Terashima M, Satoh K, Sekiyama S, Suzuki A, Eda Y, Satodate R (1995) Alterations in adenoma and differentiated adenocarcinoma of the stomach. Cancer Res 55: $1933-1936$

Toyonaga T, Nishino E, Hirooka T, Ueda C, Noda K (2006) Intraoperative bleeding in endoscopic submucosal dissection in the stomach and strategy for prevention and treatment. Digestive Endosc 18: S123-S127

Tsukashita S, Kushima R, Bamba M, Sugihara H, Hattori T (2001) MUC gene expression and histogenesis of adenocarcinoma of the stomach. Int I Cancer 94: 166 - 170

Wu M, Semba S, Li D, Yokozaki H (2004) Molecular pathological analysis of mucinous adenocarcinoma of the stomach. Pathobiology 71: 201-210

Yamamoto H, Perez-Piteira J, Yoshida T, Terada M, Itoh F, Imai K, Perucho M (1995) Gastric cancers of the microsatellite mutator type display characteristic genetic and clinical features. J Gastroenterol 16: 1348 - 1357 